\title{
LIVING WITH THE INTERNET: ETHICS IN THE NOÖSPHERE
}

\author{
Emma Rooksby and Diarmuid Pigott \\ Murdoch University \\ PO Box 776 \\ Nedlands \\ Perth \\ West Australia 6006 \\ email cmma@merriweb.com.au
}

\begin{abstract}
In this paper we present a holistic alternative to the conventional ground of existent ethical discourse on the Internet. We analyse this discourse and the model of the 'net and netizens from which it is derived, and finding it unsatisfactory, present a discourse of co-operative ethics, based on a model of the Internet as a Noetic Hyper Entity. We then examine the tradition of such entities in Westem Philosophy, and decide which of three traditions (the Preexistent, the Emergent and the Convocational) is suited to our discussion. Finally we make suggestions as to how awareness of this entity can provide incentive to act co-operatively, and conclude that the existent form of Netiquette is the best model for appropriate behaviour on the 'net.
\end{abstract}

\section{A LONE BOUNDARY-RIDER AT THE ETHICAL FRONTIER}

It is tempting to portray interaction with the Internet as a solitary indulgence, or even a solitary vice - not intrinsically good, but at best useful. Pessimistic visions of the Internet as composed of millions of self-interested users in darkened rooms in front of glowing screens direct most ethical debate to restraining individuals from acting out their base natural inclinations. Similarly, defence of the Internet is usually framed in terms of the rights of the individual user to enjoy certain freedoms, and to be protected from the incautious exercise of freedom by other individuals.

The pessimists' predictions focus on images of an increasingly selfish and alienated information-empowered elite who disenfranchise, or exploit, an information-hungry majority (see for instance, Roszak, 1989; Pawley, 1973; McLuhan and Powers, 1989; Rheingold, 1990; or even Gibson, 1985,1993). Exploitation is taken to be an inevitable outcome of conflicts among solitarily indulgent individuals. The pessimist's only distinction between the elite and the masses is in the distribution of power, in terms of the individual's ability to enact his or her selfish desires. If the Internet can be retailed as allowing the individual to be a Nietszchean Superman in an infinitude of self-created virtual worlds without fear of consequence, then entirely new forms of voluntary alienation, and concomitant retreat from community life are envisaged. Dystopian futurologist Pawley sees the self-interested future in such bleak terms:

"Alone in a centrally heated air-conditioned capsule, drugged, fed with music and erotic imagery, the parts of his consciousness separated into components which reach everywhere and nowhere, the private citizen of the future will have become one with the end of effort and the triumph of sensation divorced from action." (Pawley, 1973) The Internet is seen by the pessimist as consisting of millions of such users, logged on for the sole purpose of gratification, and not contributing to it for any other reason. Optimistically such users are exercising their right to self-expression or self-improvement. Either way, when the moral agent is taken to be solitary and self-interested, then the individual's autonomy and gratification coalesce as the only stable critcria for ethical decision-making. For critics and defenders alike, individual desires and satisfactions are taken to be the yardstick of what is good and right.

Ethics based on individual-rights or perhaps Utilitarian principles predominates on both sides of the debate about the future of the Internet. The pessimistic solution is to guard against the emergence of moral and legal no-man'sland by legislating against new forms of vice - the 'net is seen as disparate nodes wherein the storage or transmission of information forms the basis for legal and ethical evaluation. Even when ethical theorists take a positive approach to the Internet, they also take the nodal perspective. Mitchell, for instance, inclines this way in City of Bits: "the technological means to create private places in cyberspace are available but the right to create these places remains a fiercely contested area" (Mitchell, 1995).

Implicit in the approaches of both the pessimist and the optimist is a conceptual map of the Internet as consisting of self-determined nodes: the separate users and their workstations, connected via networking to hosts which facilitate the relay of information throughout a global network. This nodal map leads us to treat the Internet as a passive network permitting efficient communication between individuals engaged in isolated and discrete transactions. 
The nodal picture of the Internet relies on a reductionist ontology, in which the only respectable explanations are those that reduce systems to their constituents elements. Attached to this is a rather unpleasant portrait of human nature, a sort of autonomous Enlightenment rationality gone sour: nodal images of human society remain as a hangover from Enlightenment values of autonomy and self-determination which have governed accounts of the self and of social interaction since Descartes. Schopenhauer commented approvingly on Descartes' treatment of the self as a basis for philosophy:

"By [Descartes'] taking the cogito, ergo sum as the only certainty, the essential and only proper starting-point of all philosophy was found, at the same time its true focus, which is essentially and inevitably the subjective, the individual consciousness" (Schopenhauer, 1819).

While for Descartes, and for Schopenhauer too, this image inspired hope in the power of the self to overcome difficulty, it painted social values as irrelevant, or even oppressive to the concerns of the self. At the hands of Nietzsche, the whole of human existence was depicted as a struggle between noble self and a small-minded herdlike community. The evolutionary paradigm emerging in the life sciences in the nineteenth century reinforced this inaccurate picture of the essential nature of human relations, presenting accounts of society as embodying such antagonism (Bronowski, 1973). Even those opposed to the Newtonian-Cartesian paradigm (McMaster, 1996) have tended to presuppose its validity - see for example the work of Rouse (Rouse, 1989; also Latour, 1986). It is this nexus of misperceptions which besets us in ethical speculation about the Internet. A holistic focus on co-operation and community is long overdue.

\section{THE INTERNET TREATED AS A DYNAMIC WHOLE}

There are three main problems resulting from the nodal image of the Internet: it is incorrect ontologically, it is misleading in its expectations of the behaviour of the Internet community, and finally it seduces people into inappropriate expectations. Firstly, a problem of focus: it depicts the Internet as built of fixedly separate nodes, thereby neglecting the co-operative and dynamic aspect of the 'net as a whole. This derives from a reductionist metaphysics which holds that knowledge of systems is a matter of understanding their constituent parts, not of holistic apprehension of them. We can get some way towards dissolving the first problem by reconceiving the Internet as co-operative and dynamic. The co-operative element is already present in the networking protocol, including the hardware basis, of the entire Internet. The edifice of the 'net stands because it has at its heart a cooperative and adaptive design paradigm. In the same way a cat's cradle cannot be completely described by analysing some string and ten fingers, concentrating on isolated nodes for the purpose of analysis of the 'net loses sight of the net as a co-operative whole. All networks have a common protocol for sharing data which is in some measure holistically consistent - this is not a tautology, but rather a teleological description. The failsafe mechanism built into the original ARPANET established a networking protocol that was not only co-operative, but adaptive, so that destruction of part of the network would not destroy the whole:

"From its inception, the network was designed to be a decentralised, self-maintaining series of redundant links between computers and computer networks, capable of rapidly transmitting communications without direct human involvement or control, and with the automatic ability to re-route communications if one or more individual links were damaged or otherwise unavailable." (CDA decision, 1996)

As the ARPANET evolved into the Internet, the older protocols of mail and file transfer gave way to the more complex protocols that make up the web as we have it now. As we watch, these go to the increasingly rich and complex HTML exception set, and the interactivity of the net-based languages and operating systems. At the same time, there has from the outset been a willingness on the part of the designers of the 'net's protocols to be inclusive and co-operative (see also Mitchell, 1995). At the functional limits of the more formal Internet standards we see a proliferation of user-created consortia developing and implementing additional standards (Conklin and Newcomer, 1995).

The mapping of the Internet through Domains and Domain Names is functionally co-operative, as are the higher level protocols - FTP, UUCP, HTTP etc. This means the Internet is an entity fractally co-operative, without any central control mechanism, but with an evolving set of consistent information transfer interfaces (Conklin and Newcomer, 1995). Despite numerous varieties of OS, connections can be established and maintained. None of these protocols is easily typified as an object like the terminals described in the nodal picture of the Internet. Rather, the interaction of several levels of protocol interfaces suggests a picture of the Internet as an entity composed of cooperation-driven processes rather than of objects (Vaskevitch, 1995).

The mechanisms for change on the Internet involve co-operation: examples of co-operation in establishment of new protocols are the self-adjudicating Internet Engineering Task Force, and the many ad hoc user consortia. The process for change can proceed with great vigour, through the innocuous sounding Calls For Discussion, Calls for Votes, and Requests For Comment. Any IETF proposal at any point in time preserves its mantle of co- 
operation, maintaining the name Request for Comment even when it has been de facto accepted by millions of hosts around the world. Co-operation is also strongly encouraged in the establishment of new newsgroups, where Calls For Discussion are used; all these mechanisms are non-centralised co-operative measures used in the development of Internet forums. Most developments are public and can be commented on or contributed to by anybody. By being co-operative and adaptive, the internet employs non-centralised mechanisms which allow it its own rate of evolution. Part of those mechanisms is the co-operative nature of the human interactions: " No single entity -- academic, corporate, governmental, or non-profit -- administers the Internet. It exists and functions as a result of the fact that hundreds of thousands of separate operators of computers and computer networks independently decided to use common data transfer protocols to exchange communications and information with other computers (which in turn exchange communications and information with still other computers)" (CDA decision, 1996).

Both the co-operation inherent in the evolution of the Internet and its current non-centralised dynamic structure point to the appropriateness of a model which incorporates this dynamic co-operative aspect of the 'net. The original nodal picture simply ignored this aspect. We have here indicated a new conception of the Internet as an entity comprised of myriad non-centralised dynamic cooperative interactions.

Asynchronous manifold connections is also a processing paradigm in Cognitive Science. Co-operation is implicit in neural and other systems; antagonism is only introduced at higher levels, and as such is still considered a pathogen. Similar accounts of complex information systems are provided by Connectionism and by Complexity theories (see for example Johnson-Laird, 1988; Lewin, 1993; Kurzweil, 1990).

In addition, there is support for the idea that the order apparent in a phenomenon, such as an ant colony (Resnick, 1994), or the growth of a crystal structure (Penrose, 1989), need not be the result of a single ordering "agent", but may result from the conformity of the whole system to codes of networked communication (McMaster, 1996; Changeux, 1985). Cognitive scientist Philip Johnson-Laird argues that the apparently symbolic or logical functioning of the conscious human mind may actually overlie a level of coordinated parallel processing of non-symbolic material. At the subconscious level mental processes may, he writes, "be the parallel processing of distributed representation created by the merging of many separate experiences." (Johnson-Laird, 1988) The overall order of such systems is maintained by regular networked communication, not by the autonomy of each individual cell or process. A more detailed account of Connectionism or of Markov Systems, could be used to give further support to the picture of the Internet as a self-regulating and co-operative system, though there is insufficient space to do so here.

\section{THE FICTION OF THE SELF-INTERESTED INDIVIDUAL}

A second problem with the nodal picture of the Internet is its treatment of individuals as self-determining independent agents rather than as primarily social beings. This problem is compounded by the assumption (also common to much IRL ethical speculation) that human beings are almost entirely self-interested, and can only be induced to socially responsible or community-minded behaviour by coercion. Examination of the nature of interaction on the 'net between the people who are its users shows it not to be the self-centred exercise the nodal picture paints. The essential process of the 'net is one of dialogue - even stateless transactions such as web-pages partake of the basic communication form of the 'net, rapid asynchronous communication (Mitchell, 1995). It could be objected that people are ultimately co-operating with machines, not each other, and that machine cooperation still leaves us with isolated, or even alienated users. But this ignores the fact that terminal interfaces through the internet are only the latest in a series of asynchronous communication devices, and that previous such devices - letters and telephones - have reduced isolation and alienation. Moreover; some writers have even proposed a new evolution of consciousness into human/machine hybrids. Such systems have the capacity to move away from a myopic focus on discrete individuals. For instance, Donna Haraway's "Manifesto for Cyborgs" links optimism toward technological innovations with a manifold increase in subjective possibilities. Her "cyborg" is a potent image of the ongoing immersion of humanity in a compound multiple self whose essential nature lies in the mental realm (Haraway, 1989).

The nodal picture assumes a very stark view of man as wholly selfish and unwilling to co-operate except for selfish reasons. Apart from any effect such pessimism might have on our behaviour, it is unlikely that human socicty could function without at least a modicum of co-operation. The co-operative nature of human society is focal to communitarian ethics (see Etzioni, 1995; Glendon, 1991). It is taken to be the basis of all ethics by Ewin in Co-operation and Human Values (Ewin, 1981). He argues that co-operation is fundamental to human society not just in obviously co-operative activities like helping one another, or using a mutually agreed strategy to sort out a disagreement. Even agreeing to abide by the conventional rules for determining a strategy, or using the linguistic conventions which allow us to communicate without great misunderstanding are co-operative 
activities. "In each case, we aim at some good, the resolution of the dispute [or the sharing of opinions], and we gain it by following a procedure that requires us to accept mutual limitations" (Ewin, 1981).

Co-operation is presupposed by human society - tools such as language and reasoning are intrinsically dependent on the ability of human beings to work co-operatively. (Ewin, 1981). So although each person benefits overall from social co-operation, his or her decisions in particular circumstances are not based merely on judgements as to which action will best serve that person in the future. That is, self-interest is a minor consideration besides the good brought to all by social co-operation, and is never the only factor in decision making. He notes: "cooperation is always inter-personal, a matter of several people doing something, and not simply a matter of individual action by a lone person" (Ewin, 1981). Clearly the interactions among the many co-operative concerns which constitute a society will involve more complex issues such as loyalty - but preservation of the benefits of co-operative life necessitates self-moderation and control. This brings us to the issue of ethics in the co-operative society.

Virtues are, for Ewin, simply those qualities which contribute to or sustain the co-operative nature of society; vices are simply those qualities which detract from or damage the co-operative enterprise. Because co-operation is essential to the continuation of society, reasoning about virtues and vices is fundamental and takes priority over all other reasoning. So, for example, the smaller co-operative enterprise (say a software company) can be assessed only in relation to the greater good of society (or whatever is taken to be the greatest co-operative enterprise in existence).

Because the basis of society is co-operative rather than rule- or law-based, determinations of the best course of. action are loose, and depend on considerations of various virtues and vices which can never be formulated into strict rules (Ewin, 1981). Thus, for example, a willingness to cause pain to animals is seen as a vice, not because it may lead to ill treatment of people, but because "what is at work in both cases is a delight in causing pain" - a vice, not an infringement of a law (Ewin, 1981). So, by Ewin's account of society, co-operation is seen not merely as conducive to individual gratification, but as constitutive of the social fabric. The holistic picture of social interaction which he presents, with dynamic multi-level co-operation as conceptually fundamental, and values (or virtues) rather than rules governing behaviour, is remarkably similar to the account of networks used above to characterise the Internet.

\section{A HOLISTIC PICTURE OF THE INTERNET AS A NOETIC HYPER-ENTITY}

A third problem to tackle is the net effect of treating individuals as selfish, assuming that how we think about the world helps make the world. The nodal picture informs users of the 'net as received wisdom, and an ethical fortress mentality is induced by the apparent lack of common goals uniting users. People reason: "If others can't be relied on to co-operate, why should I?" Without a suitable holistic or dynamic concept of the Internet, ethical speculators and legislators fall back on the nodal picture of individuals as ethically autistic and in need of strict regulation. For the optimist, the best course is to legislate to ensure the survival of the Internet; for the pessimist, the clear path is to legislate to ensure the 'net's control. The Internet can acceptably be treated as a proliferation of dynamic co-operative interactions which are self-regulating. But can this amorphous mass of co-operative and dynamic interactions provide a more satisfactory basis for ethics than a conception of interested selves conducting pecuniary transactions? Ewin's account of human society as intrinsically co-operative may be more optimistic than traditional accounts of persons as selfish. But how can a dynamic and co-operative, yet inherently chaotic and unlocalised, Internet provide a sufficiently coherent entity with which to guide ethics?

The answer to this is that it must be conceived as an entity greater than any single human person. Descriptions, from both experts and novices, of the complexity and vitality of the Internet support the claim that it may best be grasped holistically, as a Gestalt entity. (So, incidentally, does the willingness of many people to believe that a centralised controlling body "in charge" of the Internet (CDA Decision, 1996)). One of the defining characteristics of any Gestalt entity is that a grasp of its essential nature includes understanding its intentional structure, its telos. A simple example of a Gestalt entity is a human being. Although we know people to be composed of various atoms, cells and organs, we best understand them as social beings with beliefs and aspirations. We could never properly understand someone we did not know by, say, dissecting their corpse. What is significant about the Internet as a Gestalt entity is that human interactions are its constituent parts, along with the information we have put into it, and the protocols we have established for that information's conveyance. This means that understanding the Internet is a matter of examining, and attempting to understand, something similar to human beings, but of a different order of magnitude. Ludwig Wittgenstein vividly describes this rather difficult concept as "the feeling of depending on an alien will" (Wittgenstein, 1961).

But even if we do treat the Internet as a semi-autonomous agent, we do not treat it as a human being. It is, for one thing, primarily immaterial. So we have chosen the term Noetic Hyper-Entity to describe entities of the order 
of the Internet. Referring to the Internet as a hyper-entity describes its status as an agent of some sort. The term noetic, meaning mental, captures the immaterial nature of the agent with which we are dealing. Western philosophy contains at least three traditions which employ the idea of a Noetic Hyper-Entity. The oldest species is the Pre-existent NHE, first documented in Plato's Timaeus: "In the centre [of the world] God put the soul, which he diffused throughout the body, making it also to be the exterior environment of $\mathrm{it}$; and he made the universe a circle moving in a circle, one and solitary, yet by reason of its excellence able to converse with itself, and needing no other friendship or acquaintance. Having these purposes in vicw he created the world a blessed god" (Plato, 1892).

Plato's World Soul is a higher order of being in the world, prior to human existence: not mercly a social construct or an explanatory mechanism, but part of the world's composition. It exists in the noetic realm, and so can only be apprehended by pure intellect, the faculty appropriate to that realm. The other two lower faculties were spirit (which apprehended thought) and appetite (which apprehended the material world). However, we can have only a dim conception of the World Soul because humans are not made up purely of intellect. Ethics is a matter of attuning the human organism to the structure of the World Soul, controlling and ordering the lower faculties of spirit and appetite by use of the intellect. The idea of a Pre-existent NHE described by Plato derived from the Pythagoreans, and was adopted by the Neoplatonists. A minor heretical doctrine in medixval theology, it re-emerged in late nineteenth century Idealism, in Fechner's panpsychism, Bergson's vitalism, and the NeoHegelianism of Royce.

The Pre-existent NHE is eternal and unchanging - this was part of its appeal to the ancient Greeks. A contrasting model is the Emergent NHE, as formulated in Hegel's Phenomenology of Spirit:

"The living substance is...truly realised and actual solely in the process of positing itself, or in mediating with its own self its transitions from one state or position to another...true reality is merely this process of reinstating self-identity, of reflecting into its own self in and from its other, and is not an original and primal unity as such, not an immediate unity as such" (Hegel, 1910).

This notion finds resonance in the work of modern Emergent Pantheists (Whitehead, Hartshorne and Lovelock) and Eschatologists such as Vernadsky and Teilhard de Chardin. It also forms the basis of much philosophical speculation in Complexity Theory, though rarely as an explicit part of the theory itself (Waldrop, 1992; Lewin, 1992). Emergent NHEs are biological or ecological formations, seen as still in the process of evolution. As in the case of the Pre-existent NHE, human desires and actions cannot influence the form the Emergent NHE takes. Thus the cellular sub-entities of the Emergent NHE (that is, individual minds) cannot prefigure its final form, nor influence its development in any way. For example, for Lovelock, consciousness may well be parasitic, while for Teilhard consciousness is a transient organic phase. Because the nature of the Emergent NHE cannot be known in advance, the ethical systems associated with it are primarily ad hoc pragmatic schemes.

The third species to be considered is the Convocational NHE, formed through human association, and not existing prior to that association. Hobbes' Nation-State, the Sovereign, is the archetypal Convocational NHE, arising from the mutual political interests of the citizens of a state, and it can be seen in Ewin's "greatest cooperative enterprise" and the "common ground" of the Communitarian ethical schemata. St. Paul's vision of the Christian Church as the Bride of Christ is also a Convocational NHE, arising from fellowship and a belief in the common good. A Convocational NHE can be conceived of as existing, but unacknowledged: the idea of an unnoticed convocational soul of the state first occurs in Plato's Republic, and also occurs in Aristotle's Politics, Rousseau's Volunté Général, and Marx's Proletariat Consciousness. Nor is the Convocational NHE a solely political entity. A human culture, including its Arts, could, for instance, be treated as a Convocational NHE, and indeed has been in Fludd's Artes Liberaliores (Godwin, 1979) and Fraser's noötemporal Umwelt (Fraser, 1975). There is no pre-existent order to which a Convocational NHE will conform, means that it can be formed to some extent by all those who participate in its being, and leaves humans partly responsible for the qualities of the NHE which eventuate from their activities. The actions of the NHE can only be traced indirectly to the actions and interactions constituting it. It should be emphasised that the Convocational NHE is usually described anthropomorphically. This makes it easier to treat holistically as a psychologically consistent entity. Ethics which employ a Convocational NHE tend to be contractual and to focus on social co-operation.

The existence of an NHE is a continuous thread of the Western intellectual tradition, and is frequently used in ethical and political theory. All the above traditions posit a NHE as a metaphysical means of guiding human ethics and politics, though each has its own way of so doing. We need to decide which one to use as a basis for cthical conduct on the Internet. The Pre-existent NHE relies on a gnostic metaphysical doctrine of creation, the Emergent NHE on the acceptance of a post-gnostic cosmology. This immediately makes them less appealing to people who do not accept such doctrines. More importantly, in order for an NHE to be of any use in guiding our conduct, a clear conception of that NHE is needed. And for both the Pre-existent and the Emergent NHEs, this conception has only ever been undertaken by ad hoc appeal to an anthropomorphic characterisation of the NHE. 
For example, the Pre-existent World Soul has been described by considering it as the semi-human Demiurge and Teilhard's Emergent Noösphere is predicted to emerge as a Point Omega Consciousness. The anthropomorphic NHE is, as we have seen, primarily associated with the Convocational species of NHE. In effect, then, the Preexistent and Emergent NHEs best function in ethics when treated as Convocational NHEs.

An additional drawback to both the Pre-existent and the Emergent NHEs is that they are taken to be entirely determined by forces other than human intentions. These forces are either purely theistic (as in Plato's Timaeus) or purely organic (like Teilhard's Noösphere). They leave little or no room for human input into the form taken by the NHE. Thus neither gives us freedom to negotiate an ethics with the NHE in question. For instance, what there is of ethics in Plato's Timaeus suggests that the human soul's goal is the attainment of the same condition as the World Soul. A Pre-existent NHE is a fixed entity, upon which the actions of humans have no influence. We cannot negotiate with a Pre-existent or an Emergent NHE. Using either as a model for the Internet would give us an ethics with very little theoretical flexibility. However, the Convocational NHE is by definition composed of deliberate human association. This model leaves at least a degree of freedom for humans to negotiate with and to determine the precise form of the NHE. This can be accomplished by treating the internet as a semi-autonomous entity, rather than ignoring its presence and activity in favour of consideration of individual human will. In conclusion of this section, the Internet is best conceived of as a Convocational NHE, a semi-autonomous entity produced by the intentional actions of a large community of people, but whose precise nature is only indirectly related to the interactions of individual members of that community. The NHEs ethical function is as a guide or reminder of our duty towards its other members.

\section{THE COVENANT}

The context of Internet ethics is that of an evolving convocational contract with a Noetic-Hyper-Entity, involving both value-based ethical norms and a set of explicit rules delineating injustice, the latter lagging some way behind normative values. (i.e. standards for virtuous behaviour). For instance, going on-line initially involves agreement to a set of service-provider conditions. As regular usage is established, the important behavioural rules and norms come into play in increasingly recognisable forms. Convocational behaviour is exhibited, for example, in the willingness of old hands to help out and guide those new to the 'net, as well as to admonish them when ethical norms are contravened. Similar normative constraints regulate the behaviour of up-stream service providers. All behaviour which falls inside the very broad category not-unjust is at least acceptable, if not the best course of action (Ewin, 1981). In those cases where an action is considered unjust, it is with regard not only to those directly affected but to the Convocational NHE itself, and by implication to all members of the NHE, including the instigator of the unjust action. Vice is unco-operative behaviour, and, as such, is damaging to the NHE as a whole. So, by our very use of the internet we find ourselves in a social contract with the NHE and, within the context of the NHE, with our peers. Tacit consent is established in the act of benefiting from membership in the community of users. And a sense of being part of a larger entity - a Convocational NHE provides overwhelming encouragement for co-operation and responsible behaviour. The co-operative origin of the Internet in scientific and academic circles has given it a firmly community-minded co-operative basis. The essence of a contract with the NHE is that each of us makes certain sacrifices in exchange for the benefits provided by the NHE. In the case of the Internet, we forgo unlimited expression and unlimited bandwidth usage in exchange for such expression and bandwidth as common usage allows. By treating this agreement as between the self and the NHE, we find ourselves responsible to all elements of the NHE, even those whom we do not know. Responsibility to a larger community than our immediate acquaintances is, as already noted, a characteristic of Convocational NHEs. On the Pauline model we act responsibly towards a larger whole through cooperating and willing the good of the enterprise. On the Hobbesian model this is achieved through voluntary restraint and respecting the importance of the nation (the largest co-operative community to which one belongs). For the Internet, the community is potentially a worldwide one.

In conclusion, by treating conformity to the co-operative nature of a Convocational NHE as the norm, we have a strong intersocial ethical basis for determining which new behaviours are virtuous and which vicious, and for responding accordingly. Anything which preserves the sense of the community of the 'net, without great detriment to other co-operative entities, is to be promoted. An on-line virtue-based ethics is already maintained by peer censure and voluntary restraint and is best maintained thereby. Netiquette and RFCs are appropriate and hitherto effective means of maintaining a regulated environment for 'net interaction. Believing in the force of the NHE to maintain and encourage co-operation with accepted 'net practises can only provide us with greater incentive to co-operate. Self-regulation, and governmental reticence are important to keeping the Internet fertile, preventing the sterility which comes with legal wrangles and administrative conformism. Some regulations are no doubt required to prevent abuse, but are unnecessary (and probably ineffective) as a means of pre-emptive 
control. The NHE has come into existence as a co-operative dynamic entity, and it, not individual persons or corporations, should be given priority in ethical decision-making.

\section{REFERENCES}

Aristotle (1972), De Generatione Animalium (trans. Balme, D.M.), Clarendon Press.

Aristotle (1959), Politics (trans. Warrington, J.), J.M.Dent \& Sons.

Bergson, H. (1914), Creative Evolution (trans. Mitchell, A.), MacMillan \& Co.

Bronowski, J. (1973), The Ascent of Man, BBC.

Campbell, J. (1982), Grammatical Man, Simon \& Schuster

Changeux, (1985), Neuronal Man: The Biology of Mind, (trans. Garey, L.), Oxford University Press.

Conklin, P. and Newcomer, E. (1995), "The Keys to the Highway" in The Future of Software (ed.

Leebaert, D.), MIT Press, 77-104.

Cunard, J.(1995), "Property of the Mind" in The Future of Software (ed. Leebaert, D.), MIT Press, 260.

Etzioni, A. (1993), The Spirit of Community: The Reinvention of American Society, Touchstone.

Ewin, R. (1981), Co-Operation and Human Values, St. Martin's Press.

Fechner, G. (1966), Elements of Psychophysics, Holt, Rinehart and Winston.

Foucault, M. (1980), Knowledge and Power: Selected Interviews and Other Writings, Harvester 'Press.

Fraser, J. (1975), Of Time, Passion and Knowledge, George Braziller.

Gibson, W. (1985), Neuromancer, Grafton.

Gibson, W. (1993), Virtual Light, Viking.

Glendon, M. (1991), Rights Talk: The Impoverishment of Political Discourse, Free Press.

Godwin, J. (1979), Robert Fludd: Hermetic philosopher and surveyor of two worlds, Thames \& Hudson.

Haraway, D. (1989), Simians, Cyborgs and Women, Routledge.

Hartshorne, C. (1984), Omnipotence and Other Theological Mistakes, SUNY Press.

Hegel, G. (1910), The Phenomenology of Mind (trans. Baillie, J.), Swan Sonnonschein.

Hobbes, T. (1914), Leviathan, Dent.

Hobbes, T. (1962), Body, Man and Citizen, Collier Books.

Johnson-Laird. P.N. (1988), The Computer and the Mind: An Introduction to Computer Science, Fontana.

Kline, G. (ed.), (1963), Alfred North Whitehead: Essays on His Philosophy, Prentice-Hall, Inc.

Kurzweil, R. (1990), The Age of Intelligent Machines, MIT Press.

Latour, B. (1986), Laboratory Life: The Construction of Scientific Facts, Princeton.

Lewin, R. (1992), Complexity: Life at the Edge of Chaos, Macmillan.

Lovelock, W. (1988), The Ages of Gaia: a Biography of our Living Earth, Norton.

Mitchell, W. (1995), City of Bits; Space, Place and the Infobahn MIT Press.

McLuhan, M., and Powers, B. (1989), The Global Village: Transformations in World Life and Media in the 21st Century, Oxford University Press.

McMaster, M. (1996), The Intelligence Advantage, Butterworth-Heinemann.

Pawley, M. (1973), The Private Future: Causes and consequences of community collapse in the

West, Thames \& Hudson.

Penrose, R. (1989), The Emperor's New Mind: Concerning Computers, Minds, and the Laws of Physics, Vintage.

Plato (1892) Dialogues (trans. Jowett, B.), Random House.

Plotinus (1929), Selected Works (trans. Mead, G.), G Bell \& Sons Ltd.

Resnick, M. (1993), Turtles, Termites and Traffic Jams: Explorations in Massively Parallel

Microworlds, MIT Press.

Rheingold, H. (1991), Virtual Reality, Martin, Secker and Warburg.

Roszak, T. (1986), The Cult of Information: The Folklore of Computers and the True Art of Thinking, Lutterworth.

Rouse, J. (1987), Knowledge and Power: Towards a Political Philosophy of Science, Cornell University Press.

Rousseau, J. (1913), The Social Contract, Dent.

Royce, T. (1908), The World and the Individual, Macmillan. 
Schopenhauer, A. (1819), The World as Will and Idea (trans. Berman, J.), Dent.

Sheldrake, R. (1983), A New Science of Life: Towards a Hypothesis of Formative Causation, Fontana.

Teilhard de Chardin, P. (1959), The Phenomenon of Man, Harper and Brothers.

Vaskevitch, D. (1995) "Is Any of this Relevant?" in The Future of Software (ed. Leebaert, D.) MIT Press, 45-76.

Wallis, R.T. (1972), Neo-Platonism: Classical Life and Letters, Charles Scribner's Sons.

Waldrop, M. (1992), Complexity, Simon \& Schuster.

Wildiers, N. (1968), An Introduction to Teilhard de Chardin, Fontana.

Wills, C. (1995), The Runaway Brain: The Evolution of Human Uniqueness, Flamingo.

Wittgenstein, L. (1961), Notebooks 1914-1916 (trans. Anscombe, G.) Basil Blackwell.

\section{ACKNOWLEDGEMENTS}

We would like to thank Callan Ledsham, Sheila Renfrey, Peter Bryant, Pasha Parpia, Jo Simpson, Brent Parkin, James Coleman, Patrick Pigott and Paul Mackin-Brown for their helpful advice and criticisms of earlier drafts of this paper. Many of their comments have been incorporated into the final piece. 